\title{
Prevention of Anastomotic Leakage in Ovarian Cancer Debulking Surgery and Its Impact on Overall Survival
}

\author{
ARNE KOSCIELNY ${ }^{1}$, ANNA KO ${ }^{1}$, EVA K. EGGER ${ }^{2}$, WALTER KUHN ${ }^{3}$, \\ JÖRG C. KALFF ${ }^{1}$ and MIGNON-DENISE KEYVER-PAIK ${ }^{2}$ \\ ${ }^{1}$ Department of Surgery, University of Bonn Medical School, Bonn, Germany; \\ ${ }^{2}$ Department of Gynecologic Oncology, University of Bonn Medical School, Bonn, Germany; \\ ${ }^{3}$ Department of Gynecology and Obstetrics, Donau-Isar-Klinikum, Deggendorf, Germany
}

\begin{abstract}
Aim: The aim of this retrospective study was to investigate the impact of anastomotic leakage on survival rate and to define potential factors of risk and protection from bowel anastomotic leakage in patients with bowel segment resection treated for epithelial ovarian cancer in an accredited high-volume center. Patients and Methods: Data of 136 patients treated with bowel resection between 2010 and 2017 were collected. All operations were performed by three accredited gynecological oncologists and by two specialized colorectal surgeons. Survival and anastomotic leakage rates were analyzed as per preoperative treatment, number and localization of anastomoses, grading of ovarian cancer, and protective loop ileostomy. Results: In total, anastomotic leakage was observed in 23 out of 165 anastomoses (13.9\%), representing 23 anastomotic leakages in 136 patients (16.9\%). The 30-day mortality rate was $0.73 \%$. There was no statistically significant difference in anastomotic leakage rate depending on localization and number of anastomoses $(p=0.634)$. Patients with a protective loop ileostomy ( $n=22 / 136$ patients) had no anastomotic leakage $(0.0 \%, p=0.021)$. The anastomotic leakage rate was significantly different in patients without protective loop ileostomy depending on bevacizumab administration [no bevacizumab: $15 / 111 \quad(13.5 \%) \quad v s . \quad$ bevacizumab administration: $4 / 8$ (50.0\%), $p=0.007]$. Tumor-positive resection margins in bowel segments were an independent prognostic factor (relative risk $=6.3 ; 95 \%$ confidence intervaI=3.1-12.9). Conclusion: In this data set, protective loop ileostomy likely reduced the anastomotic leakage rate
\end{abstract}

Correspondence to: PD Dr. Arne Koscielny, Department of Surgery, University of Bonn Medical School, Venusberg Campus 1, D-53127 Bonn, Germany. Tel: +49 22828714342, Fax: +49 22828714856, e-mail: Arne.Koscielny@ukb.uni-bonn.de

Key Words: Ovarian cancer, debulking surgery, bowel resection, anastomotic leakage, protective loop-ileostomy. after bowel resection in selected cases of ovarian cancer treated with debulking surgery. Especially in patients treated with bevacizumab, protective loop ileostomy should be considered. There was no significant impact of leakage rate on overall survival.

Epithelial ovarian cancer (EOC) is often discovered at a late stage of disease, typically spreading predominantly over the peritoneal surface of the abdomen (1). Most likely due to the physiological movement of peritoneal fluid, the majority of women present at the time of first treatment with peritoneal spread to the pouch of Douglas, the colonic gutters and the right diaphragm (2).

Treatment of advanced ovarian cancer consists of a combination of surgical resection of the tumor spread and chemotherapy. Chemotherapy courses are administered after initial surgery, although there are extensive data that a neoadjuvant approach reduces morbidity and possibly resection rates in patients with extensive disease unlikely to achieve complete cytoreduction at the time of diagnosis (3-5). In the neoadjuvant setting, typically two to three courses are administered before interval debulking surgery, and chemotherapy is completed with six up to courses after the patient has recovered from surgery (6).

Chemotherapy as first-line treatment is platinum- and taxane-based, usually in combination with the vascular endothelial growth factor inhibitor bevacizumab. Recently, however, alternative treatment regimens based on the relatively new class of poly (ADP-ribose) polymerase inhibitors have emerged (7-9).

Bevacizumab is an inhibitor of the formation of new blood vessels, principally by blocking tumor cells from signaling the body to supply the new cancer tissue with vessels. The most serious complication associated with bevacizumab treatment is impairment of physiological vessel healing through the same mechanism, potentially leading to proteinuria, high blood pressure and, most dangerously, impaired secondary wound healing and spontaneous gastrointestinal perforation in 
$1-2 \%$ of patients with ovarian cancer (10). Elective surgery should not be undertaken for at least 6 weeks after discontinuation of bevacizumab treatment, especially for colorectal surgery.

Macroscopically complete tumor resection (optimal cytoreduction) is the decisive prognostic factor in ovarian cancer treatment that can be directly influenced, while suboptimal cytoreduction is currently defined as any visible postoperative tumor independent of size (11).

In patients with late recurrent ovarian cancer, a second radical cytoreduction should be considered if optimal cytoreduction is feasible, followed again by a combination platinum-based chemotherapy. If complete cytoreduction is unlikely to be achieved, surgery should be omitted $(12,13)$. Some patients will receive bevacizumab in combination with second-line chemotherapy if they have not been treated with it before (14).

Hyperthermic intraperitoneal intraoperative chemotherapy (HIPEC) may be performed in individual cases of EOC. HIPEC is currently not a standard procedure in the treatment of ovarian cancer but it has shown some very promising results in peritoneal cancer of the colon and a first phase III trial in ovarian cancer $(15,16)$. It may be administered after debulking surgery before emergence from anesthesia as an additional measure to standard treatment and is hypothesized to overcome inherent resistance mechanisms in remaining intra-abdominal cancer cells since hyperthermia, as well as a possibly highly concentrated chemotherapy, in comparison to intravenous doses (e.g. cisplatin 1:20), are known to be highly cytotoxic (17). HIPEC has been shown to be a safe and feasible therapy, but, depending on the cytotoxic agent used, side-effects and complication rates may vary $(16,18,19)$.

Optimal cytoreduction frequently requires radical surgery of the upper gastrointestinal tract and resection of bowel segments in advanced first-line and recurrent disease, with rectosigmoidal resection being the most frequently performed $(20,21)$. In some patients, optimal cytoreduction can only be achieved by multiple segment resections of the small and large intestines $(20,22)$.

Although bowel segment resection has been shown to be feasible and safe in debulking surgery for advanced ovarian cancer, anastomotic leakage is a common severe complication after bowel resection (23). In the literature, data on rates of anastomotic leakage in EOC surgery vary considerably due to inhomogeneous treatment strategies and different patient collectives (24).

Only a small number of studies and no randomized trials have addressed the prevention of anastomotic leakage after bowel resection in EOC debulking surgery $(23,25,26)$. Data deriving from colorectal surgery suggest that protective loop ileostomy reduces anastomotic leakage in rectosigmoid resection and low rectal resection, while ileostomy-related complications need to be considered (27-29). Previous publications associate protective loop ileostomy in radical debulking surgery for ovarian cancer with acceptable morbidity and high reversal rates, without compromising long-term survival of patients $(30,31)$.

In this study, we analyzed anastomotic leakage (per patient and per anastomosis) and survival rates depending on defined risk factors after bowel segment resections in debulking surgery for epithelial ovarian cancer at a certified center, and investigated the role of protective loop ileostomy at a single high-volume center.

\section{Patients and Methods}

This was an observational study based on a prospectively managed registry. This study obtained local Ethics Committee approval (University of Bonn Medical School, Ethics Committee, no. 004/10) and patients gave appropriate informed consent to use of their data.

All patients who underwent any type of bowel resection and primary anastomosis during debulking surgery of confirmed ovarian cancer treated at our tertiary referral center between 2010 and 2017 were included in this study. Patients with debulking surgery without full circumferential bowel resection, Hartmann's procedure or other discontinuity resection without anastomosis; later diagnosis of histology other than ovarian cancer; diffuse and deep infiltration of the small bowel mesentery root; diffuse carcinomatosis of the small bowel involving such large parts that resection would lead to short-bowel syndrome (remaining bowel $<1.5 \mathrm{~m}$ ); diffuse involvement/deep infiltration of stomach/duodenum without the possibility of limited resection, or of the head or middle part of the pancreas; tumor involvement of truncus coeliacus, hepatic arteries, or left gastric artery; or with central or multiple liver and pulmonary metastases were excluded.

Data of 136 patients with EOC and colorectal with/without further bowel resections during debulking surgery were collected and analyzed. Retrospectively analyzed data were acquired by a prospectively collected Department-owned database. Therefore, the presented data are based on a single-center registry. The STROBE guidelines were fully adhered to in the reporting of our study results (32).

All patient cases were preoperatively discussed by an interdisciplinary Tumor Board according to national and international guidelines. The patients' surgical morbidity and mortality was assessed and recorded. The median follow-up was 51.7 months (range=2-105 months). All patients were followed up every 3 months at our outpatient clinic or at the gynecologists assigning to our Gynecological Department after primary surgery. If patients had discontinued follow-up examinations, the treating family doctor was contacted to obtain the necessary data.

The surgeries were performed by three Board-certified gynecological oncologists, and the bowel resections and anastomoses by two specialized colorectal surgeons.

A protective loop ileostomy was performed at the surgeon's discretion in patients undergoing more than one simultaneous bowel resection, with low performance status, estimated high blood loss $(>1,000 \mathrm{ml})$, low anastomosis $<8 \mathrm{~cm}$ from the anal verge, and long operative time ( $>8$ hours). The descendorectostomies were usually located between 6 to $10 \mathrm{~cm}$ from the anal verge. There was no obligatory algorithm used during the study period for loop ileostomy. 
Anastomotic leakage was defined as feculent secretion from drains, wound or vagina, extravasation from an anastomotic site verified by computed tomography, air exiting from drains during diagnostic rectoscopy or leakage confirmed at revision surgery.

Protective or risk factors for anastomotic leakage were analyzed, including age, operative time, perioperative serum cancer antigen125 level, perioperative $\mathrm{Hb}$ value, perioperative catecholamine administration, Féderation International de Gynécologie et d'Obstétrique (FIGO) stage, histological grading, tumor-free resection margins, recurrent ovarian cancer localization and number of anastomoses, neoadjuvant chemotherapy and bevacizumab administration, HIPEC, splenectomy, and protective loop ileostomy.

The impact of these factors on the development of intestinal anastomotic leaks was analyzed by cross tables, chi-squared test and by tests for solid effects type III using the IBM SPSS 24 statistical programme (IBM, Armonk, NY, USA). Survival rates were calculated by Kaplan-Meier analysis. The survival rates depending on risk factors were compared univariately by log-rank test and multivariately by the Cox model. Differences were considered significant p-values less than 0.05 .

\section{Results}

A total of 165 anastomoses were performed in 136 patients, of whom $104(76.5 \%)$ presented with primary ovarian cancer and $32(23.5 \%)$ with recurrent disease. The average age was $61.86 \pm 11.73$ years. The average operative time was $450.77 \pm 119.49$ minutes.

Anastomotic leakage was observed in 23 out of the 165 anastomoses $(13.9 \%)$, i.e. 23 anastomotic leakages in 136 patients $(16.9 \%)$.

The 30 -day mortality was $0.73 \%$. One patient died on the 23rd postoperative day due to pulmonary embolism, having already been discharged from hospital.

Of the 165 anastomoses, $27 \quad(16.4 \%)$ were jejunojejunostomies or ileoileostomies, 31 (18.8\%) ileocolonic anastomoses, $25(15.2 \%)$ colocolostomies, and $82(49.7 \%)$ descendorectostomies. The anastomotic leakage rate was $2 / 27$ in jejunojejunostomies or ileoileostomies $(7.4 \%$ of intestinal anastomoses and $1.2 \%$ of all anastomoses, respectively), 5/31 in ileocolonic anastomoses (16.1\% of ileocolonic anastomoses and $3.0 \%$ of all anastomoses, respectively), 4/25 in colocolonic anastomoses $(16.0 \%$ of colocolonic anastomoses and $2.4 \%$ of all anastomoses, respectively), and 12/82 in descendorectostomies (14.6\% of descendorectostomies and $7.3 \%$ of all anastomoses, respectively).

Univariate analysis of the anastomotic leakage rate showed no statistically significant difference in the localization of anastomosis $(p=0.634)$. Twelve out of 23 anastomotic leakages $(52.2 \%)$ were found in descendorectostomies. There was no statistically significant difference in anastomotic leakage rate for jejunojejunostomies and ileoileostomies $(p=0.289)$, for ileocolonic anastomoses $(p=0.715)$, colocolostomies $(p=0.632)$, and for descendorectostomies $(p=0.614)$ according to tumor-free resection margins and histological grading (Table I).
Repeat laparotomies due to recurrent EOC ( $\mathrm{n}=60,44.1 \%$, $p=0.621)$ splenectomies $\quad(\mathrm{n}=21,15.4 \%, \quad p=0.349)$, intraoperative HIPEC $(\mathrm{n}=15,11.0 \%, p=0.275)$, neoadjuvant chemotherapy $(p=0.175)$, FIGO stage $(p=0.342)$, and histological tumor grading $(p=0.211)$ also had no statistically significant impact on anastomotic leakage rate.

Four out of 19 patients $(21.1 \%)$ with bevacizumab administration 4-8 weeks prior to surgery developed anastomotic leakage, whereas 15 patients (13.1\%) without bevacizumab administration prior to surgery had a postoperative anastomotic leakage. This difference was not statistically significant $(p=0.119)$.

Anastomotic leakage occurred in $19 / 104$ patients with primary ovarian cancer, $(18.3 \%)$, and $4 / 32$ patients with recurrent ovarian cancer $(12.5 \%)$. This difference was not statistically significant $(p=0.446)$. Table I displays all results analyzed for 165 anastomoses in 136 patients.

Analysis of the subgroup of patients with advanced ovarian cancer at initial diagnosis (FIGO stages IIc, IIIb, IIIc, and IVa; Table II) revealed that in 117 patients (145 anastomoses), neoadjuvant chemotherapy and bevacizumab administration did not have an impact on the anastomotic leakage rate, while protective loop ileostomy was significantly protective against anastomotic leakage. For this group, none of the patients with anastomoses with protective loop ileostomy ( $n=22 / 136$ patients or 30/165 anastomoses) showed any anastomotic leakage $(0.0 \%)$. However, in those without protective loop ileostomy (114/136 patients or $135 / 165$ anastomoses), the anastomotic leakage rate was $17.0 \%$. This difference was statistically significant $(p=0.021)$. Twenty out of 22 patients $(90.9 \%)$ did undergo ileostomy reversal within 6 months after debulking surgery.

Separating patients into subgroups according to protective loop ileostomy revealed a statistically significant difference in the anastomotic leakage rate depending on preoperative (at the latest 4 weeks before surgery) bevacizumab administration in the non-loop ileostomy subgroup [15/111 (13.5\%) vs. 4/8 (50.0\%), $p=0.007$ ] (Table II).

The overall survival rate of the whole patient cohort was $82.9 \%$ at 1 year, $54.7 \%$ at 3 years, and $38.05 \%$ at 5 years. There was no statistically significant difference in the 5-year overall survival rates between patients with $(n=23,34.8 \%)$ and without $(\mathrm{n}=113,38.6 \%, p=0.737)$ anastomotic leakage. Recurrent ovarian cancer, histological grading, protective loop ileostomy, and splenectomy had no significant impact on the survival rate in the univariate analysis. However, the number of anastomoses performed during one operation, tumor-free resection margins in resected bowel segments, localization of anastomoses, and bevacizumab administration showed significant effects on the survival rate in the univariate analysis (Table III). The survival rate for patients with more than one anastomosis per operation was significantly lower $(56.5 \%$ vs. $88.0 \%$ at 1 year, $25.4 \%$ vs. 
Table I. Protective and risk factors for anastomotic leakage in all 165 anastomoses (cross tables and test for solid effects type III).

\begin{tabular}{|c|c|c|c|c|c|c|}
\hline \multirow{3}{*}{ Risk factor } & & \multicolumn{4}{|c|}{ Anastomotic leakage } & \multirow{3}{*}{$p$-Value } \\
\hline & & \multicolumn{2}{|c|}{ Without } & \multicolumn{2}{|c|}{ With } & \\
\hline & & $\mathrm{N}$ & $\%$ & $\mathrm{~N}$ & $\%$ & \\
\hline \multirow[t]{2}{*}{ Ovarian cancer } & Primary $(n=123)$ & 104 & 84.6 & 19 & 15.4 & 0.321 \\
\hline & Recurrent $(n=42)$ & 38 & 90.5 & 4 & 9.5 & \\
\hline \multirow[t]{4}{*}{ Localization of anastomosis } & Jejunojejunostomy $(\mathrm{n}=27)$ & 25 & 92.6 & 2 & 7.4 & 0.634 \\
\hline & Ileocolonic anastomosis $(\mathrm{n}=31)$ & 26 & 83.9 & 5 & 16.1 & \\
\hline & Colocolostomy $(\mathrm{n}=25)$ & 21 & 84.0 & 4 & 16.0 & \\
\hline & Descendorectostomy $(\mathrm{n}=82)$ & 70 & 85.4 & 12 & 14.6 & \\
\hline \multirow[t]{2}{*}{ Number of anastomosis } & $1(n=110)$ & 93 & 84.5 & 17 & 15.4 & 0.286 \\
\hline & $>1(\mathrm{n}=26)$ & 20 & 76.9 & 6 & 23.0 & \\
\hline \multirow[t]{4}{*}{ Jejunojejunostomy } & Tumor-free margins $(\mathrm{n}=22)$ & 21 & 95.5 & 1 & 4.5 & 0.158 \\
\hline & Tumor-positive margins $(n=4)$ & 3 & 75.0 & 1 & 25.0 & \\
\hline & FIGO G1/2 (n=15) & 15 & 100.0 & 0 & 0.0 & 0.068 \\
\hline & FIGO G3/4 $(n=4)$ & 3 & 75.0 & 1 & 25.0 & \\
\hline \multirow[t]{4}{*}{ Ileocolonic anastomosis } & Tumor-free margins $(\mathrm{n}=22)$ & 18 & 81.8 & 4 & 18.2 & 0.932 \\
\hline & Tumor-positive margins $(n=6)$ & 4 & 80.0 & 1 & 20.0 & \\
\hline & FIGO G1/2 $(n=18)$ & 16 & 88.9 & 2 & 11.1 & 0.365 \\
\hline & FIGO G3/4 $(n=8)$ & 6 & 75.0 & 2 & 25.0 & \\
\hline \multirow[t]{4}{*}{ Colocolostomy } & Tumor-free margins $(\mathrm{n}=16)$ & 14 & 87.5 & 2 & 12.5 & 0.456 \\
\hline & Tumor-positive margins $(n=4)$ & 4 & 100.0 & 0 & 0.0 & \\
\hline & FIGO G1/2 $(n=16)$ & 14 & 87.5 & 2 & 12.5 & 0.259 \\
\hline & FIGO G3/4 $(n=6)$ & 4 & 66.7 & 2 & 33.3 & \\
\hline \multirow[t]{4}{*}{ Descendorectostomy } & Tumor-free margins $(n=67)$ & 57 & 85.1 & 10 & 14.9 & 0.760 \\
\hline & Tumor-positive margins $(n=9)$ & 8 & 88.9 & 1 & 11.1 & \\
\hline & FIGO G1/2 $(n=55)$ & 47 & 85.5 & 8 & 14.5 & 0.567 \\
\hline & FIGO G3/4 (n=12) & 11 & 91.7 & 1 & 8.3 & \\
\hline \multirow[t]{2}{*}{ Neoadjuvant chemotherapy } & No $(n=82)$ & 67 & 81.7 & 15 & 18.3 & 0.257 \\
\hline & Yes $(\mathrm{n}=81)$ & 73 & 90.1 & 8 & 9.9 & \\
\hline \multirow[t]{2}{*}{ Bevacizumab administration } & No $(n=135)$ & 127 & 87.0 & 19 & 13.0 & 0.229 \\
\hline & Yes $(n=30)$ & 15 & 78.9 & 4 & 21.1 & \\
\hline \multirow{2}{*}{ Protective loop ileostomy } & No $(n=135)$ & 112 & 83.0 & 23 & 17.0 & 0.021 \\
\hline & Yes $(n=30)$ & 30 & 100.0 & 0 & 0.0 & \\
\hline \multirow[t]{2}{*}{ HIPEC } & No $(n=146)$ & 127 & 87.0 & 19 & 13.0 & 0.275 \\
\hline & Yes $(\mathrm{n}=19)$ & 15 & 78.9 & 4 & 21.1 & \\
\hline
\end{tabular}

HIPEC: Hyperthermic intraperitoneal intraoperative chemotherapy.

$39.9 \%$ at 5 years, $p=0.028)$. As there were only three patients with three anastomoses, interpretation of results for this small group is limited. Patients with tumor-free resection margins in the bowel segments survived significantly longer compared to patients with tumor-positive resection margins $(49.6 \pm 3.5$ vs. $18.4 \pm 3.8$ months; $p<0.001)$. Bevacizumab administration was associated with a significantly shorter survival of patients (22.7 \pm 4.1 vs. 52.4 \pm 4.1 months, $p=0.021)$ after debulking surgery. If the anastomosis involved the small bowel, the survival rate was significantly reduced $(0.0 \%$ and $8.9 \%$, respectively, at 5 years) compared to patients without small bowel anastomosis $(64.4 \%$ and $43.1 \%$, respectively, at 5 years; $p<0.001$ ) in the univariate analysis (Table III).

In the multivariate analysis according to the Cox model including the risk factors anastomotic leakage, number of anastomoses, tumor-free resection margin, bevacizumab administration, neoadjuvant chemotherapy, protective loop ileostomy, localization of anastomosis, HIPEC and recurrent ovarian cancer, only the tumor-positive margins of the resected bowel segments was an independent prognostic factor with a 6.3-fold (95\% confidence interval=3.1-12.9) higher relative mortality risk in patients with tumor-positive resection margins compared to those with tumor-free margins (Table IV).

\section{Discussion}

Ovarian cancer is typically diagnosed at a late stage with bowel resection being a necessity in a majority of patients. This makes anastomotic leakage a typical and one of the 
Table II. Protective and risk factors for anastomotic leakage in 145 anastomoses for combined Féderation Internationale de Gynécologie et d'Obstétrique stages IIc, IIIb, IIIc, IVa (test for solid effects type III).

\begin{tabular}{|c|c|c|c|c|c|c|c|}
\hline \multirow[b]{3}{*}{ Risk factor } & & & \multicolumn{4}{|c|}{ Anastomotic leakage } & \multirow{3}{*}{$p$-Value } \\
\hline & & & \multicolumn{2}{|c|}{ Without } & \multicolumn{2}{|c|}{ With } & \\
\hline & & & $\mathrm{N}$ & $\%$ & $\mathrm{~N}$ & $\%$ & \\
\hline \multirow[t]{4}{*}{ Therapy } & \multirow[t]{2}{*}{ Neoadjuvant chemotherapy } & No $(n=65)$ & 54 & 83.1 & 11 & 16.9 & 0.175 \\
\hline & & Yes $(n=78)$ & 70 & 89.7 & 8 & 10.3 & \\
\hline & \multirow[t]{2}{*}{ Bevacizumab } & No $(n=128)$ & 113 & 88.3 & 15 & 11.7 & 0.119 \\
\hline & & Yes $(n=17)$ & 13 & 76.5 & 4 & 23.5 & \\
\hline \multirow[t]{14}{*}{ Protective loop ileostomy } & \multirow{3}{*}{$\begin{array}{l}\text { No }(\mathrm{n}=119) \\
\text { Bevacizumab }\end{array}$} & & 100 & 84.0 & 19 & 16.0 & 0.033 \\
\hline & & No $(\mathrm{n}=111)$ & 96 & 86.5 & 15 & 13.5 & 0.007 \\
\hline & & Yes $(n=8)$ & 4 & 50.0 & 4 & 50.0 & \\
\hline & \multirow[t]{2}{*}{ Neoadjuvant chemotherapy } & No $(n=51)$ & 40 & 78.4 & 11 & 21.6 & 0.117 \\
\hline & & Yes $(n=68)$ & 60 & 88.2 & 8 & 11.7 & \\
\hline & \multirow[t]{2}{*}{ With bevacizumab } & With chemotherapy & 2 & 1.4 & 2 & 1.4 & \\
\hline & & Without chemotherapy & 2 & 1.4 & 2 & 1.4 & \\
\hline & \multirow[t]{2}{*}{ Without bevacizumab } & With chemotherapy & 58 & 26.6 & 9 & 4.2 & \\
\hline & & Without chemotherapy & 38 & & & 6.3 & \\
\hline & Yes $(n=26)$ & & 26 & 100.0 & 0 & 0 & \\
\hline & \multirow{2}{*}{ With bevacizumab } & With chemotherapy & 4 & 2.8 & & & \\
\hline & & Without chemotherapy & 5 & 3.5 & & & \\
\hline & \multirow[t]{2}{*}{ Without bevacizumab } & With chemotherapy & 8 & 5.6 & & & \\
\hline & & Without chemotherapy & 9 & 6.3 & & & \\
\hline
\end{tabular}

most severe complications after cytoreductive surgery. Anastomotic leakage after bowel resection in debulking surgery for ovarian epithelial cancer is described affecting overall survival and the start of adjuvant chemotherapy (23, 24). We recorded an overall anastomotic leakage rate of $13.9 \%[15.4 \%(19 / 123)$ in primary ovarian cancer and $9.5 \%$ (4/42) in recurrent ovarian cancer] related to the number of anastomoses performed. Published rates are $4-14.0 \%$, with most authors calculating the leakage rates considering all patients operated on for ovarian cancer regardless of bowel resection or all patients and not according to anastomosis $(20,23,25,31,33-36)$. We found no statistically significant differences in leakage rates among the different localizations of anastomosis, although small bowel anastomosis was less often associated with anastomotic leakage. Leakage was also less likely, but not significantly reduced in patients with tumor-free resection margins, or grade $1 / 2$ tumors. There was also no significant difference in anastomotic leakage rate between patients after neoadjuvant chemotherapy, preoperative bevacizumab administration and patients without preoperative therapy.

Anastomotic leakage has been shown to be an independent prognostic factor (hazard ratio=2.13) for reduction of overall survival of patients after debulking surgery for ovarian cancer (23). As delayed start of adjuvant chemotherapy and the impact of anastomotic leakage sequelae on the performance status of patients are responsible for this, anastomotic leakage should be avoided at all cost $(23,31)$. In our recent study, and consistent with our previous publications, we showed that bowel resections are associated with higher complication rates compared to patients without bowel resection $(31 \%$ vs. $9.8 \%, p=0.013)$ and that multiple bowel resections $(\geq 2)$ correlated significantly with increased anastomotic leakage $(16.7 \%$ vs. $2.6 \%, p=0.02)$ and mortality (16.7\% vs. 0\%, $p=0.04$ ) (37).

In this analysis, we showed that protective loop ileostomy significantly reduced the anastomotic leakage rate to $0 \%$ $(0 / 30)$ compared to a leakage rate of $17.0 \%(23 / 135)$ in patients without loop ileostomy. This difference was statistically significant $(p=0.021)$. The same finding was described in a prospective observational study by Kalogera et $a l$. as they established temporary diversion in patients with preoperative albumin $\leq 3 \mathrm{~g} / \mathrm{dl}$, prior pelvic radiation, rectosigmoidal resection plus additional large bowel resection, anastomosis $\leq 6 \mathrm{~cm}$ from the anal verge, failed leak test or contamination of the pelvis with stool. In their study, short-term outcomes were not different between diverted and non-diverted patients and stoma-related complications were observed in $25.9 \%$, principally related to dehydration. The ileostomy takedown rate in our analysis was $90.9 \%$ and compares well to the observed reversal rate of $88.9 \%$ in literature (30). In contrast to our findings, Tseng et al. could not find significantly different leakage rates in patients with and without diversion ( $5 \%$ vs. $7 \%, p=0.60)$, with comparable 
Table III. Survival rates of 136 analyzed patients according to risk factors (applicable data).

\begin{tabular}{|c|c|c|c|c|c|c|}
\hline & $\mathrm{n}$ & $\begin{array}{l}\text { Mean } \pm \text { SD survival } \\
(95 \% \mathrm{CI}), \text { months }\end{array}$ & $\begin{array}{l}1 \text { Year } \\
\text { survival }\end{array}$ & $\begin{array}{l}3 \text { Years } \\
\text { survival }\end{array}$ & $\begin{array}{l}5 \text { Years } \\
\text { survival }\end{array}$ & $p$-Value \\
\hline Total group & $(n=136)$ & $50.4 \pm 3.9(42.7-58.1)$ & $82.9 \%$ & $54.7 \%$ & $38.0 \%$ & \multirow{3}{*}{0.737} \\
\hline \multirow[t]{2}{*}{ Anastomotic leakage } & Yes $(n=23)$ & $43.4 \pm 8.3(27.1-59.6)$ & $73.9 \%$ & $55.7 \%$ & $34.8 \%$ & \\
\hline & No $(n=113)$ & $51.0 \pm 4.3(42.6-59.4)$ & $84.7 \%$ & $54.3 \%$ & $38.6 \%$ & \\
\hline \multirow[t]{2}{*}{ Recurrent ovarian cancer } & Yes $(n=32)$ & $34.3 \pm 5.1(24.2-44.3)$ & $71.1 \%$ & $59.9 \%$ & $28.8 \%$ & \multirow[t]{2}{*}{0.134} \\
\hline & No $(n=104$ & $52.7 \pm 4.3(44.3-61.1)$ & $86.4 \%$ & $56.8 \%$ & $40.4 \%$ & \\
\hline \multirow{3}{*}{$\begin{array}{l}\text { Number of anastomoses performed } \\
\text { during one operation }\end{array}$} & $1,(\mathrm{n}=110)$ & $53.6 \pm 4.4(44.9-62.2)$ & $88.0 \%$ & $58.1 \%$ & $39.9 \%$ & \multirow[t]{3}{*}{0.028} \\
\hline & $2,(n=23)$ & $32.3 \pm 6.7(19.0-45.5)$ & $56.5 \%$ & $38.0 \%$ & $25.4 \%$ & \\
\hline & $3,(n=3)$ & $37.0 \pm 16.3(5.1-68.9)$ & $100.0 \%$ & $50.0 \%$ & $50.0 \%$ & \\
\hline \multirow{2}{*}{$\begin{array}{l}\text { Tumor-free resection margins } \\
\text { in bowel segments }\end{array}$} & Yes $(n=106)$ & $49.6 \pm 3.5(42.8-56.5)$ & $84.6 \%$ & $63.1 \%$ & $42.9 \%$ & \multirow[t]{2}{*}{$<0.001$} \\
\hline & No $(n=15$ & $18.4 \pm 3.8(10.9-25.8)$ & $60.0 \%$ & $15.0 \%$ & $0.0 \%$ & \\
\hline \multirow[t]{2}{*}{ Splenectomy } & Yes $(n=21)$ & $52.2 \pm 5.7(41.1-63.2)$ & $90.5 \%$ & $72.6 \%$ & $45.4 \%$ & \multirow[t]{2}{*}{0.239} \\
\hline & No $(n=115)$ & $49.0 \pm 4.3(40.7-57.4)$ & $81.4 \%$ & $51.6 \%$ & $36.9 \%$ & \\
\hline \multirow[t]{2}{*}{ Protective loop ileostomy } & Yes $(n=22)$ & $47.4 \pm 11.4(25.0-69.8)$ & $68.2 \%$ & $44.8 \%$ & $33.6 \%$ & \multirow[t]{2}{*}{0.271} \\
\hline & No $(n=114)$ & $49.5 \pm 3.7(42.3-56.7)$ & $85.7 \%$ & $56.5 \%$ & $39.3 \%$ & \\
\hline \multirow[t]{2}{*}{ Histological grading } & $\mathrm{G} 1 / 2(\mathrm{n}=90)$ & $49.8 \pm 4.6(40.8-58.8)$ & $84.1 \%$ & $55.8 \%$ & $38.7 \%$ & \multirow[t]{2}{*}{0.441} \\
\hline & $\mathrm{G} 3 / 4(\mathrm{n}=24)$ & $57.0 \pm 8.1(41.2-73.0)$ & $91.7 \%$ & $57.4 \%$ & $43.0 \%$ & \\
\hline \multirow[t]{2}{*}{ Neoadjuvant chemotherapy } & Yes $(n=66)$ & $42.4 \pm 4.4(33.7-51.0)$ & $84.5 \%$ & $46.8 \%$ & $32.2 \%$ & \multirow[t]{2}{*}{0.163} \\
\hline & No $(n=70)$ & $54.1 \pm 5.4(43.5-64.8)$ & $85.7 \%$ & $61.9 \%$ & $43.2 \%$ & \\
\hline \multirow[t]{2}{*}{ Bevacizumab administration } & Yes $(n=15)$ & $22.7 \pm 4.1(14.7-30.6)$ & $60.0 \%$ & $46.7 \%$ & $23.3 \%$ & \multirow[t]{2}{*}{0.021} \\
\hline & No $(\mathrm{n}=121)$ & $52.4 \pm 4.1(44.3-60.4)$ & $85.7 \%$ & $56.2 \%$ & $40.0 \%$ & \\
\hline \multirow[t]{4}{*}{ Localization of anastomoses } & Jejunojejunostomy/Ileoileostomy $(\mathrm{n}=16)$ & $30.0 \pm 6.3(17.7-42.4)$ & $55.6 \%$ & $29.8 \%$ & $0.0 \%$ & \multirow[t]{4}{*}{$<0.001$} \\
\hline & Ileocolonic $(n=23)$ & $24.2 \pm 6.1(12.2-36.1)$ & $54.7 \%$ & $17.9 \%$ & $8.9 \%$ & \\
\hline & Colocolostomy $(n=22)$ & $74.1 \pm 8.7(65.1-91.2)$ & $100.0 \%$ & $90.0 \%$ & $64.4 \%$ & \\
\hline & Descendorectostomy $(n=75)$ & $50.6 \pm 4.5(41.8-59.5)$ & $91.9 \%$ & $60.5 \%$ & $43.1 \%$ & \\
\hline
\end{tabular}

CI: Confidence intervaI; SD: standard deviation.

postoperative complication and re-admission rates (31). Data on avoiding anastomotic leakage by loop ileostomy in debulking surgery with bowel resection are inconsistent, most likely due to the fact that patient numbers in these analyses are small and criteria for establishing ileostomy are inhomogeneous. A systematic Cochrane review and metaanalysis of colorectal literature showed a $67 \%$ relative risk reduction of clinically significant anastomotic leakage by protective loop ileostomy (38). Overall, while risk reduction of detectable anastomotic leakage with diverting stoma is still widely debated, there is consensus on protective stoma preventing the severe consequence of leakage, while reducing morbidity, emergency reoperation rates, intensive care unit admission, and mortality (25). Most authors recommend a diverting stoma during debulking surgery in patients with more than one bowel resection, serum albumin $<3 \mathrm{~g} / \mathrm{dl}$, previous pelvic radiation, low rectal resection with anastomosis $\leq 6 \mathrm{~cm}$ from the anal verge, poor nutritional status, and high-dosage steroid use $(25,31)$. Lago et al. found higher age at surgery [odds ratio $(\mathrm{OR})=1.046]$, lower serum albumin level $(\mathrm{OR}=0.621)$, one or more additional small bowel resections $(\mathrm{OR}=3.544)$, manual anastomosis $(\mathrm{OR}=8.356)$ and greater distance of anastomosis from the anal verge $(\mathrm{OR}=0.839)$ to be independent risk factors and recommend avoidance of hand-sewn anastomosis and a restrictive stoma policy based on presence of risk factors (36).

Bevacizumab is a common drug used in the therapy of patients with ovarian cancer with good results in prolonging progression-free survival but failure to demonstrate significant impact on overall survival. The drug is known to cause spontaneous perforations of the gastrointestinal tract in up to $3 \%$ of treated patients (39). The general consensus is to apply it either onwards from the second course of chemotherapy after first surgery or in the recurrent setting in naïve patients with the same precaution so as not to impair wound healing via VEGF-antibody treatment. We are a tertiary referral center and individual patients might be transferred after starting chemotherapy outside our care. In this analysis, 19 patients received bevacizumab before surgery. We generally adhere to a 6-week weaning period from last bevacizumab application to surgery.

In patients without loop ileostomy, we showed that preoperative administration of bevacizumab was associated with a significantly higher anastomotic leakage rate $[50.0 \%$ (4/8) vs. $13.5 \%$ (15/111), $p=0.007]$, whereas neoadjuvant chemotherapy and HIPEC did not significantly influence the anastomotic leakage rate in that subgroup. Komiyama et al. did not observe any anastomotic leakage in 23 patients 
Table IV. Multivariate analysis of risk factors for survival in association with anastomotic leakage (Cox analysis), significance of model $<0.001$.

\begin{tabular}{|c|c|c|}
\hline Factor & HR $(95.0 \% \mathrm{CI})$ & $p$-Value \\
\hline \multicolumn{3}{|l|}{ Anastomotic leakage } \\
\hline No & $0.898(0.422-1.913)$ & 0.780 \\
\hline \multicolumn{3}{|l|}{ Number of anastomoses } \\
\hline 1 & 1 & 0.226 \\
\hline 2 & $1.444(0.189-11.055)$ & 0.723 \\
\hline 3 & $2.431(0.302-19.551)$ & 0.404 \\
\hline \multicolumn{3}{|l|}{ Tumor-free resection margins } \\
\hline No & $6.315(3.095-12.886)$ & $<0.001$ \\
\hline \multicolumn{3}{|l|}{ Bevacizumab administration } \\
\hline Yes & $1.119(0.425-2.945)$ & 0.819 \\
\hline \multicolumn{3}{|l|}{ Protective loop ileostomy } \\
\hline No & $1.581(0.739-3.379)$ & 0.238 \\
\hline Localization of anastomoses & & $<0.001$ \\
\hline Small bowel & $0.001(0.000-15,560)$ & 0.896 \\
\hline Ileoascendostomy & $11.704(0.000-12.000)$ & 0.850 \\
\hline Large bowel & $16.419(0.00-17.000)$ & 0.829 \\
\hline \multicolumn{3}{|l|}{ Descendorectostomy } \\
\hline Yes & $1.427(0.000-15.600)$ & 0.978 \\
\hline \multicolumn{3}{|l|}{ HIPEC } \\
\hline Yes & $0.147(0.010-1.239)$ & 0.083 \\
\hline \multicolumn{3}{|l|}{ Recurrent cancer } \\
\hline No & $0.998(0.417-2.389)$ & 0.99 \\
\hline
\end{tabular}

CI: Confidence interval; HR: hazard ratio; HIPEC: hyperthermic intraperitoneal chemotherapy.

enrolled for a feasibility study of neoadjuvant chemotherapy combined with bevacizumab before interval debulking surgery (40). Yoshioka et al. found that colorectal anastomosis was the only independent predictive risk factor (hazard ratio $=8.285, p=0.013$ ) for major complications, such as anastomotic leakage, in patients with advanced colorectal cancer after preoperative bevacizumab administration (41). Nakamura et al. reported a significantly negative impact on intestinal anastomotic healing after bevacizumab administration in rabbits regarding the bursting pressure of small bowel anastomoses, microvessel counts in the anastomotic tissue, expression of $\alpha$-smooth muscle actin and the degree of collagen deposition in the anastomotic tissue (42). However, all reports on the effects of preoperative bevacizumab administration on anastomotic healing include only restricted numbers of cases. The same limitation applies to this analysis, thus general conclusions cannot be drawn.

Neoadjuvant chemotherapy has been proven to be safe and feasible concerning rates of anastomotic leakage. Phase III trials did not show an increased rate of complications in comparison to adjuvant settings $(3,4)$.

HIPEC has been analyzed in many different settings in ovarian cancer, but only very limited high quality data have been published to date. However, a published phase I trial of recurrent EOC at our Institution showed no increase of anastomotic leakage rate and one phase III trial in the firstline setting also concurred with our findings that HIPEC has no negative impact on bowel resection complications (16, 19). Yet conclusions have to be drawn with caution, since any change of intraoperative chemotherapy agent or HIPEC technique might possibly produce different feasibility or safety results (43).

In this analysis, overall survival was influenced by the number of anastomoses performed during debulking surgery ( $1 v s .>1$ ), the localization of anastomoses (small bowel vs. large bowel), bevacizumab administration and tumor-negative $v s$. tumor-positive resection margins in bowel segments.

Rectosigmoidal resection is the most common form of bowel resection in debulking surgery due to the early peritoneal metastasis in the pouch of Douglas. It usually achieves good results (20). The necessity of small bowel resections in ovarian cancer in terms of anastomosis localization and number is due to the spread of carcinosis outside of the pelvis and outside of the physiological flow of the peritoneal fluid from the pouch of Douglas through the colonic gutters to the diaphragm. This represents generalized tumor spread, often with significant ascites, and with significantly worse survival rates $(23,36,44)$.

Additionally, bevacizumab administration was also associated with significantly reduced overall survival in our patients $(23.3 \%$ vs. $40.0 \%, p=0.021)$. At our Institution, during the analyzed interval, in accordance with the three large phase III trials GOG 0218, ICON 7 and OCEANS (7, $8,14)$, bevacizumab was administered to the following groups of patients: bevacizumab-naïve with platinumsensitive recurrent disease, and patients with suboptimal cytoreduction. These patients represent the largest group of patients on bevacizumab in this analysis and therefore are a surrogate for those with a poor prognosis.

In conclusion, all significant findings in the univariate analysis mainly reflect the severity and generalization of ovarian cancer.

In our multivariate analysis, only tumor-positive margins in bowel segments had a significant impact on the overall survival of our patients $(\mathrm{RR}=6.315 ; 95 \% \mathrm{CI}=3.095-12.886)$. Tumor-free margins are certainly intended during debulking surgery but tumor involvement of the bowel wall is not always detectable during surgery, even by on-site frozen section. In addition, the extent of bowel resection is limited by the risk of short-bowel syndrome and often by the patient's agreement to ostomy creation. There was no significant difference in anastomotic leakage rates between those with tumor-negative and those with tumor-positive anastomotic margins. However, this might have been due to the small number of cases. To our knowledge, there are no recent studies addressing the correlation of tumor-free resection margins, anastomotic leakage and overall survival in patients with ovarian cancer. 
This study was based on data from a prospectively collected Department-owned database and the typical limits of small numbers, single-center data and retrospective analysis apply. Confounders, such as different tumor biology, comorbidities, and different surgical techniques were addressed and minimized whenever possible.

Although this was not a prospectively randomized trial and the decision for establishing a protective loop ileostomy was left at the surgeon's discretion, the strength of this analysis is its very homogenous treatment strategy within a single center with only five surgeons in an interdisciplinary team treating all patients.

In order to define recommendations for protective loop ileostomy in debulking surgery for ovarian cancer and especially for patients undergoing bevacizumab therapy, prospective trials are needed.

\section{Conclusion}

Within the limits of retrospective analyses of prospectively acquired registry data of a single tertiary referral center, protective loop ileostomy was found to reduce the anastomotic leakage rate after bowel resection in selected cases of debulking surgery for ovarian cancer. Patients with preoperative bevacizumab treatment may be at high risk of anastomotic leakage and protective loop ileostomy should be considered for this group. Tumor-positive resection margins of resected bowel segments was the only independent prognostic factor for poorer overall survival. Further multicenter studies with standardized indications for loop ileostomy and perioperative settings are needed.

\section{Conflicts of Interest}

No conflicts of interest, financial or otherwise, exist as declared by the Authors. Sources of funding for publication and/or research: None specific

\section{Authors' contributions}

AK conceived the principal idea, played leading role in designing and writing the surgical parts of article and performed statistical analysis, AK collected data, performed statistical anaylsis and performed reference research, EKE, WK, and JCK supervised the work and contributed to the design and implementation of the study, to the analysis and interpretation of results, and to the writing of the article. MDKP conceived together with AK the principal idea, played a key role in co-writing and checking the parts of article on gynecology. All Authors discussed the results and commented on the article.

\section{Acknowledgements}

The constructive collaboration and assistance of Dr. Rolf Fimmers, Deputy Head of the Institute of Medical Biometry, Informatics, and
Epidemiology (IMBIE) at the University of Bonn Medical School, in our statistical analyses deserves our grateful acknowledgement.

\section{References}

1 Torre LA, Trabert B, DeSantis CE, Miller KD, Samimi G, Runowicz CD, Gaudet MM, Jemal A and Siegel RL: Ovarian cancer statistics, 2018. CA Cancer J Clin 68(4): 284-296, 2018. PMID: 29809280. DOI: $10.3322 /$ caac. 21456

2 Pannu HK and Oliphant M: The subperitoneal space and peritoneal cavity: Basic concepts. Abdom Imaging 40(7): 27102722, 2015. PMID: 26006061. DOI: 10.1007/s00261-015-04295

3 Vergote I, Trope CG, Amant F, Kristensen GB, Ehlen T, Johnson $\mathrm{N}$, Verheijen RH, van der Burg ME, Lacave AJ, Panici PB, Kenter GG, Casado A, Mendiola C, Coens C, Verleye L, Stuart GC, Pecorelli S and Reed NS: Neoadjuvant chemotherapy or primary surgery in stage IIIC or IV ovarian cancer. N Engl J Med 363(10): 943-953, 2010. PMID: 20818904. DOI: 10.1056/NEJMoa0908806

4 Kehoe S, Hook J, Nankivell M, Jayson GC, Kitchener H, Lopes T, Luesley D, Perren T, Bannoo S, Mascarenhas M, Dobbs S, Essapen S, Twigg J, Herod J, McCluggage G, Parmar M and Swart AM: Primary chemotherapy versus primary surgery for newly diagnosed advanced ovarian cancer (CHORUS): An openlabel, randomised, controlled, non-inferiority trial. Lancet 386(9990): 249-257, 2015. PMID: 26002111. DOI: 10.1016/ S0140-6736(14)62223-6

5 Wright AA, Bohlke K, Armstrong DK, Bookman MA, Cliby WA, Coleman RL, Dizon DS, Kash JJ, Meyer LA, Moore KN, Olawaiye AB, Oldham J, Salani R, Sparacio D, Tew WP, Vergote I and Edelson MI: Neoadjuvant chemotherapy for newly diagnosed, advanced ovarian cancer: Society of Gynecologic Oncology and American Society of Clinical Oncology Clinical Practice Guideline. J Clin Oncol 34(28): 3460-3473, 2016. PMID: 27502591, DOI: 10.1200/JCO.2016.68.6907

6 Polcher M, Mahner S, Ortmann O, Hilfrich J, Diedrich K, Breitbach GP, Hoss C, Leutner C, Braun M, Mobus V, Karbe I, Stimmler P, Rudlowski C, Schwarz J and Kuhn W: Neoadjuvant chemotherapy with carboplatin and docetaxel in advanced ovarian cancer - a prospective multicenter phase II trial (PRIMOVAR). Oncol Rep 22(3): 605-613, 2009. PMID: 19639211. DOI: $10.3892 /$ or_00000479

7 Burger RA, Brady MF, Bookman MA, Fleming GF, Monk BJ, Huang H, Mannel RS, Homesley HD, Fowler J, Greer BE, Boente M, Birrer MJ, Liang SX and Gynecologic Oncology Group: Incorporation of bevacizumab in the primary treatment of ovarian cancer. N Engl J Med 365(26): 2473-2483, 2011. PMID: 22204724. DOI: 10.1056/NEJMoa1104390

8 Perren TJ, Swart AM, Pfisterer J, Ledermann JA, PujadeLauraine E, Kristensen G, Carey MS, Beale P, Cervantes A, Kurzeder C, du Bois A, Sehouli J, Kimmig R, Stahle A, Collinson F, Essapen S, Gourley C, Lortholary A, Selle F, Mirza MR, Leminen A, Plante M, Stark D, Qian W, Parmar MK, Oza $\mathrm{AM}$ and Investigators I: A phase 3 trial of bevacizumab in ovarian cancer. N Engl J Med 365(26): 2484-2496, 2011. PMID: 22204725. DOI: 10.1056/NEJMoa1103799

9 Moore K, Colombo N, Scambia G, Kim BG, Oaknin A, Friedlander M, Lisyanskaya A, Floquet A, Leary A, Sonke GS, Gourley C, Banerjee S, Oza A, Gonzalez-Martin A, Aghajanian 
C, Bradley W, Mathews C, Liu J, Lowe ES, Bloomfield R and DiSilvestro P: Maintenance olaparib in patients with newly diagnosed advanced ovarian cancer. N Engl J Med 379(26): 2495-2505, 2018. PMID: 30345884. DOI: 10.1056/NEJM oa1810858

10 Rossi L, Verrico M, Zaccarelli E, Papa A, Colonna M, Strudel $\mathrm{M}$, Vici P, Bianco $\mathrm{V}$ and Tomao F: Bevacizumab in ovarian cancer: A critical review of phase III studies. Oncotarget $8(7)$ : 12389-12405, 2017. PMID: 27852039. DOI: 10.18632/ oncotarget. 13310

11 Thigpen T, duBois A, McAlpine J, DiSaia P, Fujiwara K, Hoskins W, Kristensen G, Mannel R, Markman M, Pfisterer J, Quinn M, Reed N, Swart AM, Berek J, Colombo N, Freyer G, Gallardo D, Plante M, Poveda A, Rubinstein L, Bacon M, Kitchener H and Stuart GC: First-line therapy in ovarian cancer trials. Int J Gynecol Cancer 21(4): 756-762, 2011. PMID: 21543937. DOI: 10.1097/IGC.0b013e31821ce75d

12 Harter P, Hahmann M, Lueck HJ, Poelcher M, Wimberger P, Ortmann O, Canzler U, Richter B, Wagner U, Hasenburg A, Burges A, Loibl S, Meier W, Huober J, Fink D, Schroeder W, Muenstedt K, Schmalfeldt B, Emons G and du Bois A: Surgery for recurrent ovarian cancer: Role of peritoneal carcinomatosis: Exploratory analysis of the DESKTOP I Trial about risk factors, surgical implications, and prognostic value of peritoneal carcinomatosis. Ann Surg Oncol 16(5): 1324-1330, 2009. PMID: 19225844. DOI: $10.1245 / \mathrm{s} 10434-009-0357-0$

13 Chi DS, McCaughty K, Diaz JP, Huh J, Schwabenbauer S, Hummer AJ, Venkatraman ES, Aghajanian C, Sonoda Y, AbuRustum NR and Barakat RR: Guidelines and selection criteria for secondary cytoreductive surgery in patients with recurrent, platinum-sensitive epithelial ovarian carcinoma. Cancer 106(9): 1933-1939, 2006. PMID: 16572412. DOI: 10.1002/cncr.21845

14 Aghajanian C, Blank SV, Goff BA, Judson PL, Teneriello MG, Husain A, Sovak MA, Yi J and Nycum LR: OCEANS: A randomized, double-blind, placebo-controlled phase III trial of chemotherapy with or without bevacizumab in patients with platinum-sensitive recurrent epithelial ovarian, primary peritoneal, or fallopian tube cancer. J Clin Oncol 30(17): 20392045, 2012. PMID: 22529265. DOI: 10.1200/JCO.2012.42.0505

15 Verwaal VJ, van Ruth S, de Bree E, van Sloothen GW, van Tinteren H, Boot H and Zoetmulder FA: Randomized trial of cytoreduction and hyperthermic intraperitoneal chemotherapy versus systemic chemotherapy and palliative surgery in patients with peritoneal carcinomatosis of colorectal cancer. J Clin Oncol 21(20): 3737-3743, 2003. PMID: 14551293. DOI: 10.1200/ JCO.2003.04.187

16 van Driel WJ, Koole SN, Sikorska K, Schagen van Leeuwen JH, Schreuder HWR, Hermans RHM, de Hingh I, van der Velden J, Arts HJ, Massuger L, Aalbers AGJ, Verwaal VJ, Kieffer JM, Van de Vijver KK, van Tinteren H, Aaronson NK and Sonke GS: Hyperthermic intraperitoneal chemotherapy in ovarian cancer. N Engl J Med 378(3): 230-240, 2018. PMID: 29342393. DOI: 10.1056/NEJMoa1708618

17 Markman M: Intraperitoneal antineoplastic drug delivery: Rationale and results. Lancet Oncol 4(5): 277-283, 2003. PMID: 12732164. DOI: $10.1016 / \mathrm{S} 1470-2045(03) 01074-\mathrm{X}$

18 Helm CW: Current status and future directions of cytoreductive surgery and hyperthermic intraperitoneal chemotherapy in the treatment of ovarian cancer. Surg Oncol Clin N Am 21(4): $645-$ 663, 2012. PMID: 23021722. DOI: 10.1016/j.soc.2012.07.007
19 Zivanovic O, Abramian A, Kullmann M, Fuhrmann C, Coch C, Hoeller T, Ruehs H, Keyver-Paik MD, Rudlowski C, Weber S, Kiefer N, Poelcher ML, Thiesler T, Rostamzadeh B, Mallmann M, Schaefer N, Permantier M, Latten S, Kalff J, Thomale J, Jaehde U and Kuhn WC: HIPEC ROC I: A phase I study of cisplatin administered as hyperthermic intraoperative intraperitoneal chemoperfusion followed by postoperative intravenous platinumbased chemotherapy in patients with platinum-sensitive recurrent epithelial ovarian cancer. Int J Cancer 136(3): 699-708, 2015. PMID: 24895230. DOI: 10.1002/ ijc.29011

20 Peiretti M, Bristow RE, Zapardiel I, Gerardi M, Zanagnolo V, Biffi R, Landoni F, Bocciolone L, Aletti GD and Maggioni A: Rectosigmoid resection at the time of primary cytoreduction for advanced ovarian cancer. A multi-center analysis of surgical and oncological outcomes. Gynecol Oncol 126(2): 220-223, 2012. PMID: 22555105. DOI: 10.1016/j.ygyno.2012.04.030

21 Chi DS, Eisenhauer EL, Zivanovic O, Sonoda Y, Abu-Rustum NR, Levine DA, Guile MW, Bristow RE, Aghajanian C and Barakat RR: Improved progression-free and overall survival in advanced ovarian cancer as a result of a change in surgical paradigm. Gynecol Oncol 114(1): 26-31, 2009. PMID: 19395008. DOI: 10.1016/j.ygyno.2009.03.018

22 Clayton RD, Obermair A, Hammond IG, Leung YC and McCartney AJ: The Western Australian experience of the use of en bloc resection of ovarian cancer with concomitant rectosigmoid colectomy. Gynecol Oncol 84(1): 53-57, 2002. PMID: 11748976. DOI: 10.1006/gyno.2001.6469

23 Grimm C, Harter P, Alesina PF, Prader S, Schneider S, Ataseven B, Meier B, Brunkhorst V, Hinrichs J, Kurzeder C, Heitz F, Kahl A, Traut A, Groeben HT, Walz M and du Bois A: The impact of type and number of bowel resections on anastomotic leakage risk in advanced ovarian cancer surgery. Gynecol Oncol 146(3): 498503, 2017. PMID: 28610745. DOI: 10.1016/j.ygyno. 2017.06.007

24 Keyver-Paik MD, Zivanovic O, Rudlowski C, Holler T, Wolfgarten M, Kubler K, Schroder L, Mallmann MR, Polcher $\mathrm{M}$ and Kuhn W: Interval debulking surgery in patients with Federation of Gynecology and Obstetrics (FIGO) stage IIIC and IV ovarian cancer. Onkologie 36(6): 324-332, 2013. PMID: 23774146. DOI: $10.1159 / 000351256$

25 Kalogera E, Dowdy SC, Mariani A, Weaver AL, Aletti G, Bakkum-Gamez JN and Cliby WA: Multiple large bowel resections: Potential risk factor for anastomotic leak. Gynecol Oncol 130(1): 213-218, 2013. PMID: 23578541. DOI: 10.1016/ j.ygyno.2013.04.002

26 Richardson DL, Mariani A and Cliby WA: Risk factors for anastomotic leak after recto-sigmoid resection for ovarian cancer. Gynecol Oncol 103(2): 667-672, 2006. PMID: 16797684. DOI: $10.1016 /$ j.ygyno.2006.05.003

27 Pisarska M, Gajewska N, Malczak P, Wysocki M, Witowski J, Torbicz G, Major P, Mizera M, Dembinski M, Migaczewski M, Budzynski A and Pedziwiatr M: Defunctioning ileostomy reduces leakage rate in rectal cancer surgery - systematic review and meta-analysis. Oncotarget 9(29): 20816-20825, 2018. PMID: 29755692. DOI: $10.18632 /$ oncotarget.25015

28 Mrak K, Uranitsch S, Pedross F, Heuberger A, Klingler A, Jagoditsch M, Weihs D, Eberl T and Tschmelitsch J: Diverting ileostomy versus no diversion after low anterior resection for rectal cancer: A prospective, randomized, multicenter trial. Surgery 159(4): 1129-1139, 2016. PMID: 26706610. DOI: 10.1016/j.surg.2015.11.006 
29 Ihnat P, Gunkova P, Peteja M, Vavra P, Pelikan A and Zonca P: Diverting ileostomy in laparoscopic rectal cancer surgery: High price of protection. Surg Endosc 30(11): 4809-4816, 2016. PMID: 26902615. DOI: 10.1007/s00464-016-4811-3

30 Kalogera E, Nitschmann CC, Dowdy SC, Cliby WA and Langstraat CL: A prospective algorithm to reduce anastomotic leaks after rectosigmoid resection for gynecologic malignancies. Gynecol Oncol 144(2): 343-347, 2017. PMID: 27919575. DOI: 10.1016/j.ygyno.2016.11.032

31 Tseng JH, Suidan RS, Zivanovic O, Gardner GJ, Sonoda Y, Levine DA, Abu-Rustum NR, Tew WP, Chi DS and Long Roche $\mathrm{K}$ : Diverting ileostomy during primary debulking surgery for ovarian cancer: Associated factors and postoperative outcomes. Gynecol Oncol 142(2): 217-224, 2016. PMID: 27261325. DOI: 10.1016/j.ygyno.2016.05.035

32 von Elm E, Altman DG, Egger M, Pocock SJ, Gotzsche PC, Vandenbroucke JP and Initiative S: The strengthening the reporting of observational studies in epidemiology (STROBE) statement: Guidelines for reporting observational studies. J Clin Epidemiol 61(4): 344-349, 2008. PMID: 18313558. DOI: 10.1016/j.jclinepi.2007.11.008

33 Braicu EI, Sehouli J, Richter R, Pietzner K, Denkert C and Fotopoulou C: Role of histological type on surgical outcome and survival following radical primary tumour debulking of epithelial ovarian, fallopian tube and peritoneal cancers. Br J Cancer 105(12): 1818-1824, 2011. PMID: 22045193. DOI: 10.1038/bjc.2011.455

34 Chi DS, Zivanovic O, Levinson KL, Kolev V, Huh J, Dottino J, Gardner GJ, Leitao MM, Jr., Levine DA, Sonoda Y, Abu-Rustum NR, Brown CL and Barakat RR: The incidence of major complications after the performance of extensive upper abdominal surgical procedures during primary cytoreduction of advanced ovarian, tubal, and peritoneal carcinomas. Gynecol Oncol 119(1): 38-42, 2010. PMID: 20609464. DOI: 10.1016/ j.ygyno.2010.05.031

35 Fotopoulou C, Zang R, Gultekin M, Cibula D, Ayhan A, Liu D, Richter R, Braicu I, Mahner S, Harter P, Trillsch F, Kumar S, Peiretti M, Dowdy SC, Maggioni A, Trope C and Sehouli J: Value of tertiary cytoreductive surgery in epithelial ovarian cancer: An international multicenter evaluation. Ann Surg Oncol 20(4): 1348-1354, 2013. PMID: 23054114. DOI: 10.1245/ s10434-012-2673-Z

36 Lago V, Fotopoulou C, Chiantera V, Minig L, Gil-Moreno A, Cascales-Campos PA, Jurado M, Tejerizo A, Padilla-Iserte P, Malune ME, Di Donna MC, Marina T, Sanchez-Iglesias JL, Olloqui A, Garcia-Granero A, Matute L, Fornes V and Domingo S: Risk factors for anastomotic leakage after colorectal resection in ovarian cancer surgery: A multi-centre study. Gynecol Oncol, 2019. PMID: 30952369. DOI: 10.1016/j.ygyno.2019.03.241
37 Oseledchyk A, Hunold LE, Mallmann MR, Domrose CM, Abramian A, Debald M, Kaiser C, Kiefer N, Putensen C, Pantelis D, Fimmers R, Kuhn W, Schafer N and Keyver-Paik MD: Impact of extended primary surgery on suboptimally operable patients with advanced ovarian cancer. Int J Gynecol Cancer 26(5): 873-883, 2016. PMID: 27101586. DOI: 10.1097/ IGC.0000000000000707

38 Montedori A, Cirocchi R, Farinella E, Sciannameo F and Abraha I: Covering ileo- or colostomy in anterior resection for rectal carcinoma. Cochrane Database Syst Rev 5: CD006878, 2010. PMID: 20464746. DOI: 10.1002/14651858.CD006878.pub2

39 Bottoni C, Scambia G, Fagotti A and Petrillo M: The safety of bevazicumab for the treatment of ovarian cancer. Expert Opin Drug Saf 17(11): 1107-1113, 2018. PMID: 30286624. DOI: 10.1080/14740338.2018.1532500

40 Komiyama S, Kugimiya T and Kubushiro K: Safety and efficacy of neoadjuvant chemotherapy containing bevacizumab and interval debulking surgery for advanced epithelial ovarian cancer: A feasibility study. J Surg Oncol 118(4): 687-693, 2018. PMID: 30206937. DOI: 10.1002/jso.25187

41 Yoshioka Y, Uehara K, Ebata T, Yokoyama Y, Mitsuma A, Ando $\mathrm{Y}$ and Nagino $\mathrm{M}$ : Postoperative complications following neoadjuvant bevacizumab treatment for advanced colorectal cancer. Surg Today 44(7): 1300-1306, 2014. PMID: 23942819. DOI: $10.1007 / \mathrm{s} 00595-013-0686-2$

42 Nakamura H, Yokoyama Y, Uehara K, Kokuryo T, Yamaguchi J, Tsuzuki $\mathrm{T}$ and Nagino $\mathrm{M}$ : The effects of bevacizumab on intestinal anastomotic healing in rabbits. Surg Today 46(12): 1456-1463, 2016. PMID: 27172973. DOI: 10.1007/s00595-0161342-4

43 Pomel C, Ferron G, Lorimier G, Rey A, Lhomme C, Classe JM, Bereder JM, Quenet F, Meeus P, Marchal F, Morice P and Elias D: Hyperthermic intra-peritoneal chemotherapy using oxaliplatin as consolidation therapy for advanced epithelial ovarian carcinoma. Results of a phase II prospective multicentre trial. Chipovac study. Eur J Surg Oncol 36(6): 589-593, 2010. PMID: 20466507. DOI: 10.1016/j.ejso.2010.04.005

44 Bartl T, Schwameis R, Stift A, Bachleitner-Hofmann T, Reinthaller A, Grimm $\mathrm{C}$ and Polterauer S: Predictive and prognostic implication of bowel resections during primary cytoreductive surgery in advanced epithelial ovarian cancer. Int J Gynecol Cancer 28(9): 1664-1671, 2018. PMID: 30371563. DOI: $10.1097 / \mathrm{IGC} .0000000000001369$

Received July 21, 2019

Revised August 7, 2019

Accepted August 14, 2019 